\title{
Improving Collaborative Learning and Global Project Management in Small and Medium Enterprises
}

\author{
http://dx.doi.org/ijac.v4i4.1726 \\ Marcus Birkenkrahe, Stefanie Quade and Frank Habermann \\ Berlin School of Economics and Law, Berlin, Germany
}

\begin{abstract}
Globalization needs Collaboration. In a multinational setting traditional issues of collaboration are exacerbated because of language and culture. This problem is particularly felt by small and medium-sized enterprises (SMEs), which are traditionally not "natural born globals". For example in Germany, which is dominated by SMEs, experience skill shortages as a result of demographic changes and a declining amount of students in engineering and informatics disciplines are becoming a major challenge. To investigate this situation, develop, and implement solutions, the research project "InterComp SME 2.0" was created. We present models and knowledge management methods to improve the training lifecycle of multi-national SMEs using interactive virtual 3-dimensional worlds such as Second Life. We focus on the case of an already globalized, medium-sized German publishing software firm. Existing training offers are modeled using business process management methods and modularised to improve execution and learning in an intercultural setting. Additional support for our approach is provided by our recent teaching experiences in a practice supervision course at the Berlin School of Economics and Law.
\end{abstract}

Index Terms-Multi-National, Collaboration, Project Management, Second Life

\section{INTRODUCTION}

In the past the traditional course of studies was a good foundation for an entire working life. Today, every employee must regularly and frequently refresh his or her qualifications in order to be up-to-date. In addition to the latest technology skills, applicable knowledge in a globalized world requires the competence to manage projects all over the world dealing with different cultures. Germany, whose economical success is fueled by a highly skilled work force, is beginning to experience the need for lifelong learning and on-the-job training. Not developing in these areas will severely hamper Germany's competitiveness. Even for small and medium-sized companies, continuing education is one of the most important conditions for innovation and success. If you would ask a manager of an SME with international operations, you would most likely hear, that (s)he knows about the need for continuous training and education. They are conscious of the importance of knowledge acquisition and open minded towards learning in virtual communities (Habermann, 2005). Ubiquitous Learning is possible today by means of elearning technologies, but benefit, quality and economic sustainability are central criteria for the company's deci- sion to invest in it (Breitner, 2010). Companies want to see directly how e-learning tools pay off - without having to become experts in rapidly changing technologies. The integration of e-learning in the management process is one of the main levers to turn this technology into business operations (Schloesser, 2010).

Together with its science and business partners, the Berlin School of Economics and Law (BSEL) has recently begun a corporate research project in the field of ELearning. Funded by the Germany Ministry of Education and Research, the project InterComp SME 2.0 is focusing on the development of modularized training offers for SMEs at the interface of information technology and culture (Birkenkrahe, 2009). Just as most lecturers still use Powerpoint presentations as the main tool of electronic delivery, most companies still limit their training presentations to Powerpoint slides. In this paper, we are investigating the case of a medium-sized, global software development firm serving the publishing industry, whose training methods are largely based on sharing several hundred slides with its clients during a two-day face-to-face course at the end of the software product implementation project. Both clients and trainers emerge exhausted and demotivated from the training. Though the clients are also trained using a test system of the software to be deployed, both clients and software company are aware that the training process could be hugely improved.

In this context, the software company is interested firstly in (a) increasing the number of trainings at a distance, and (b) making the face-to-face training sessions more effective.

More specifically, the following main goals for training optimization have been agreed among the business partner and our research team.

As Fig. 1 shows, the Training should move

- from Powerpoint to modern tools of delivery

- from high to low individual preparation effort

- from functional to process descriptions

- from two languages manual to multi-language

- from training without evaluation and continuous learning performance management.

We base this paper on our findings gained during the first phase of our systemic action research applied to faceto-face training on a specific software implementation training.

To get an overview of the training lifecycle, we analyzed an exemplary training setting. For any business 


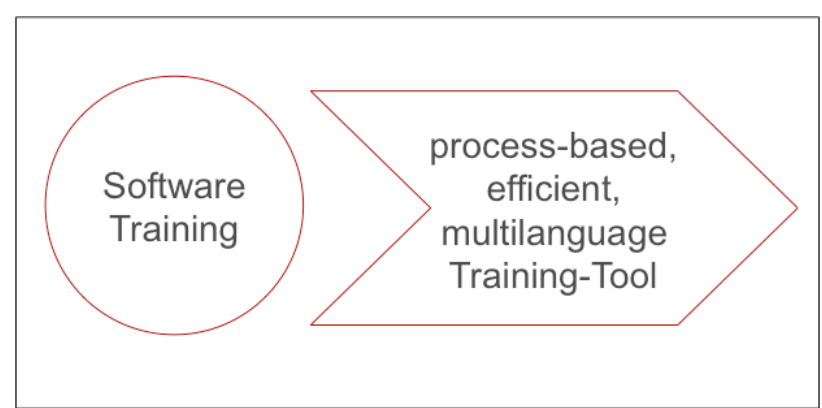

Figure 1. Software Training, initial situation

software vendor, the complexity of the business software product results in intensive training for the end-user (i.e. the employees of the corporate customer). In our research case, the specific software module deals with the complex subject of managing "Contracts, Rights and Royalties" (CR\&R). This CR\&R module is part of an even more complex enterprise resource planning (ERP) suite, which supports all business processes of a publishing company. When implementing the business software, fruitful training of key users is one of the main success criteria for system acceptance and productivity. Unfortunately, because of release changes and frequent upgrades, traditional training material in the form of Powerpoint slides becomes quickly outdated, inconsistent, and redundant. The material then falls into disarray or must be reengineered by individuals at high personal cost, leading to additional loss of energy and quality of the training.

Support for our direction of investigation - optimizing face-to-face training by combining means of e-learning methods and methodology - comes, perhaps not unexpectedly, from academic teaching: at BSEL, one of Germany's largest business schools, we have recently begun to teach courses full-time in a virtual classroom located in the virtual 3D world of Second Life (Birkenkrahe and Gallo, 2011).

These courses were supported also by an open source learning management system (Moodle) and by open source blogging software (WordPress). All three of these are the most widespread tools in their respective fields, and all three belong to an e-learning portfolio that's easily in reach of any SME. For our initial enquiry, we were interested only in the virtual reality part of the course taught at BSEL - partly because the use of learning management software and blogs has already been fairly well researched, while the use of virtual worlds in project management and company training has not. Our specific research questions were thus:

1. What are the key challenges of face-to-face training as part of a multi-national software implementation project?

2. Which lessons from teaching in interactive virtual 3D environments can be transferred to company training?

3. Can virtual 3D worlds be used to improve learning in international project management settings and deliver ubiquitous learning?

In the remainder of the paper, we present first research results in the context of questions (1) and (2), accompanied by a status analysis and give a preliminary answer to question (3), which provides a direction for future research. Question (1) deals with the company training situ-

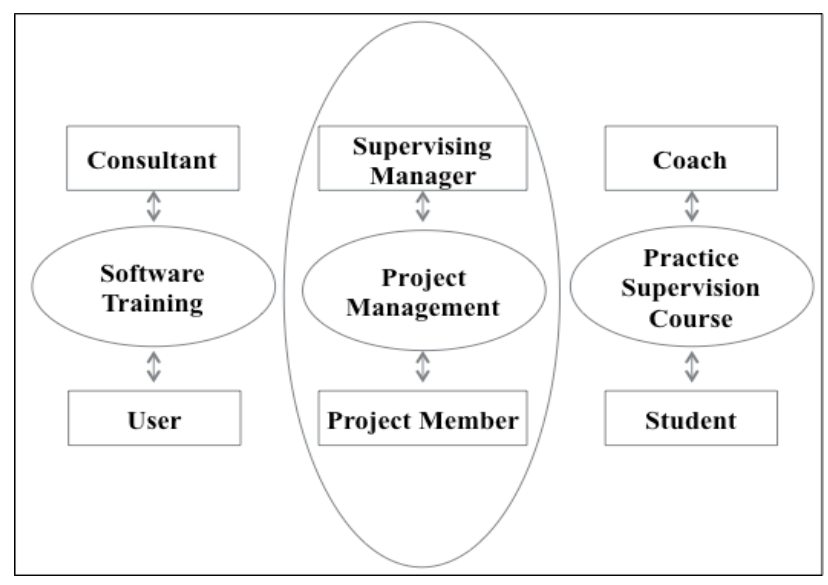

Figure 2. Overview Project Management

ation, question (2) with a practice supervision course, and (3) combines both perspectives.

Fig. 2 illustrates how these three aspects relate to one another, using "project management" as the highest level of abstraction of which the other two training situations are merely instantiations.

\section{METHODS}

For the company training and for the practice supervision, we used two different methodologies adapted to the different circumstances and research questions.

\section{A. Company training}

Within the large research setting of InterComp SME 2.0, we analyzed the training optimization using systemic action research (Brydon-Miller M., 2003) over a period of three months. To get an overview of how the training proceeds in a given setting, one of us (S.Q.) carried out a participant observation (Mayring, 2002) at a medium sized publishing house where the software company, a business partner of the research project InterComp SME 2.,0 implemented their publishing software. A consultant of this software company executed the training. After this participant observation phase, a narrative interview (Cavana, 2001) with a group of international consultants who work with the software daily, followed. The interview in the form of a telephone conference, was based on the first observation results. Interview participants received a half standardized interview guideline document in advance for preparation.

\section{B. Practice Supervision}

During the summer term 2010, we accompanied a practice supervision course of seventeen (17) graduate students in a Bachelors' program "International Business Management", who worked in different locations across Europe. The program is geared towards providing the students with more than the average amount of international experience. The course was taught by one of us (M.B.). Its point of presence consisted of weekly meetings in the virtual 3D world Second Life where BSEL occupies two islands for virtual teaching purposes (Birkenkrahe, 2010). The weekly meetings lasted 90 minutes each and took place over a period of eighteen (18) weeks. In addition, the students were asked to write weekly blog posts (using WordPress blogging software) to report on their experiences during the internship. Course materials, discussion 
forums and exercises, usually in the form of preparations for the virtual classroom sessions, were also made available online using a Moodle platform. While we already have experiences using blogs and learning platforms, this was the first course taught at the school using an interactive virtual 3d environment. The data presented and discussed in this paper are focused on developing marketing activities for virtual teaching (Gallo, 2010; Plagemann, 2010). The students were asked to fill in anonymous online surveys during the first and the last week of the course. Both surveys offered the opportunity for free responses as well.

Our investigation can be classified as Participatory Action Research (PAR) in the sense of Freire (BrydonMiller, 2003), with a noted, explicit emphasis on the fact that both test persons and researcher were part of the same community and giving rise to an "action-reflection" sequence of research learning. For example, the course participants both in the SME and in the school were informed about the purpose and nature of the investigation before and kept informed during and after the research data were obtained.

\section{RESULTS}

Because our research brings together two initially very different experimental situations - software training in an SME, and practice supervision in a business school - we will present the results from both of these in sequence before attempting an interpretation of the results in the light of improving project management methods in the discussion section.

\section{A. Company Training}

We used (a) participant observation and (b) narrative interview to obtain our results in the case of the company training setting.

\section{1)Participant Observation}

To get an overview, how the training setting proceeds, we ran a participant observation (Mayring, 2002) at a medium sized publishing house.

The software company, which is part of the research project InterComp SME 2.0 implemented their publishing software at this client. A consultant of this software company, specialized in the software application, executed the training. Before the observation started, the research team acquainted itself with the software content. The training material (Powerpoint slides, user manual) was provided by the software company. The goal of our observation was focused on the questions: How is the training environment? What atmosphere exists between consultant and user? How do they follow the setting? What main group reactions can be noticed?

The training setting was distributed over two days. On the first day (Fig 3), a group of 6 female employees from the rights purchase department were trained.

On the second day, 2 persons ( 1 male, 1 female) from the rights sales department got an introduction to the software. The training took place at a seminar room of the customer. All training members sat at a round table in this room. The consultant projected the software test on a screen. Two of the six members of the first training day brought their own laptop. Two researchers joined the groups on both days.

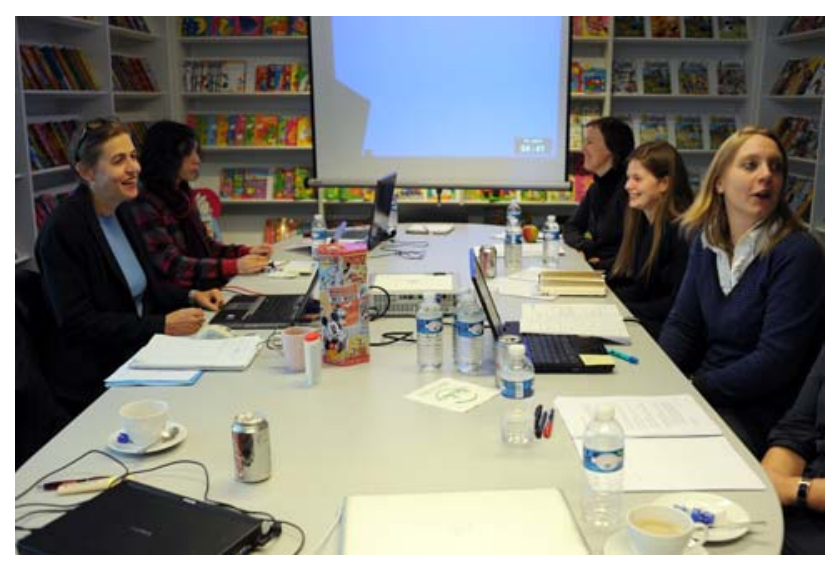

Figure 3. Observation of a Software Training

After a short overview on the structure of the system, the consultant started to simulate processes at the test system. The consultant seemed to know the needs of the training members very well because of the previous training they had received by her. She encouraged the group to ask questions in between, if they don't understand a task. Complex processes have been explained and demonstrated at a flip chart.

\section{2)Narrative Interview}

Our observation analysis provided the basis for the questions of the interview guideline, we sent to the interview member in advance. The narrative interview (Cavana, 2001) took place with a wider range of consultants three weeks after the first impressions of the observation.

Relating to the first results, the goal of the second analysis was to get a more detailed information about the complete training lifecycle. What steps does the consultant do at which part of the cycle, relevant for the training execution? Which aspects influence the preparation, execution and follow-up of the training? What are the most critical issues? What causes distress?

The narrative interview took place at a seminar room of the business partner. Three (3) researchers, one (1) project manager and one (1) consultant of the business partner sat at a round table. Three (3) international consultants were switched on in addition over the loudspeaker via a telephone conference. The interview was recorded digitally to analyze the details afterwards.

After a short introduction through the business partner's project manager and one researcher, each consultant told in narrative form about his or her experience with training courses. The interview participants were well prepared because of an interview guideline, which had been emailed to everyone in advance. All aspects of the guideline had been discussed. In addition to the half structured guideline the interview was open enough for free, narrative stories and new aspects from the participant side.

The information of the participant observation (a) and the narrative interview (b) also delivered the necessary data for the following workflow model of the software training (Fig. 4).

Each consultant (Fig. 4, on the left side symbolized by $1,2,3)$ prepares the software training in a very individual way for their customer (Fig. 4, on the right side symbolized by a,b,c). Some consultant compile a part of the prepared Powerpoint slides and use the test system (Fig. 4, 
PPM-Symbol). A few only use the test system and some combine some slides with data from the company internal content management system (Fig. 4, ST4-Symbol). There is a need for didactic and educational skills to handle different target groups, state of knowledge and characters. The evaluation is scheduled, but rarely executed after the training. Support after the training is carried out through each consultant, but the information of the support cases don't flow back into a centralized point in the company.

Next to the question, how and in which way the training material and the handouts could be worked out differently, the main problems of the face-to-face training do not concern the content (Fig. 5). The consultants would appreciate guidance on how to handle the training group psychologically, didactically and pedagogically.

\section{B. Practice Supervision}

The purpose of this course was to support the participants in their industry practice internships. To do this, a number of topical areas formed the basis of the curriculum, including skills like: communication with superiors, team members and customers; giving and getting feedback; presenting in front of a team; role playing conflict situations; analyzing conflicts, developing and implementing solutions in the work place.

Before the start of the course, each student was asked to register him- or herself independently in Second Life and create their own avatar. During virtual classroom sessions, the student would be present via his or her avatar.

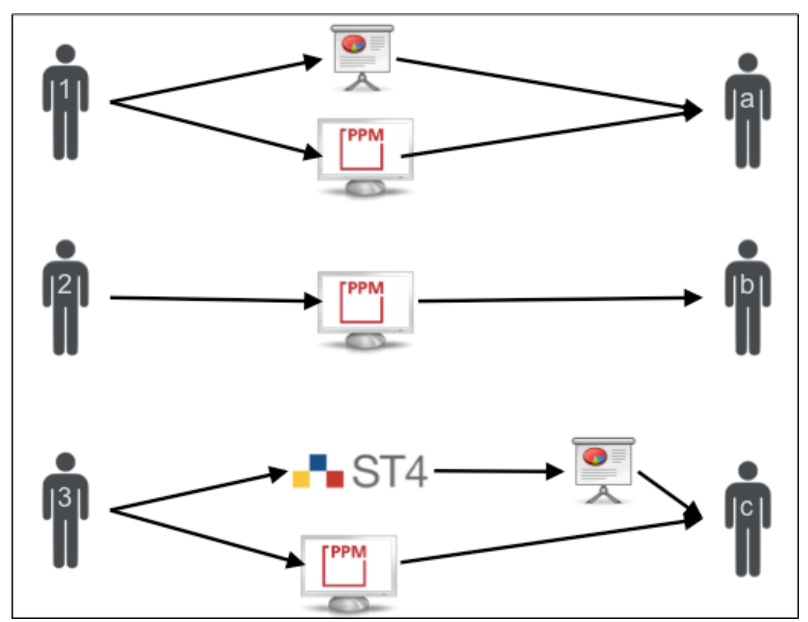

Figure 4. Software Training Workflow

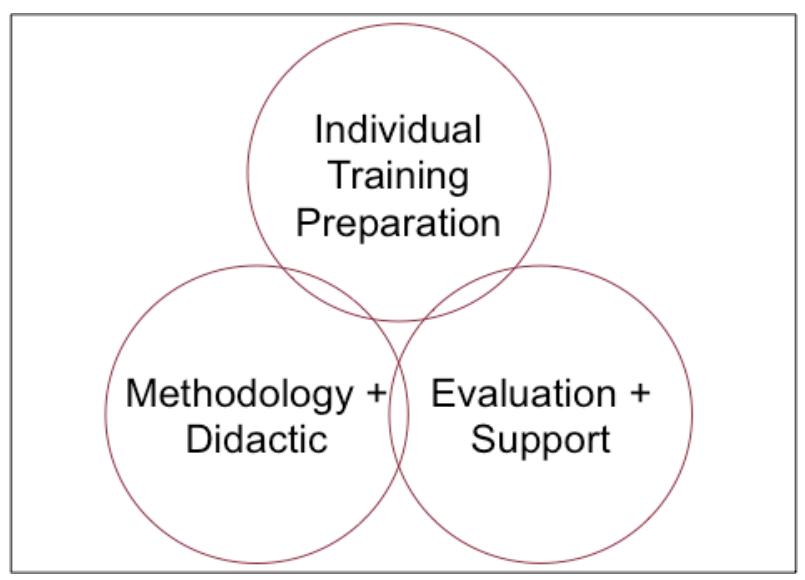

Figure 5. Main Problem Fields
In their internships, the students worked mostly in projects, usually in the position of the inexperienced team member (though there were a few exceptions). In the course of their internships, which would typically last six months, they experienced a number of issues that we've already mentioned above, and that are typical for project management group issues. The following story was shared by one of the participants and shows the level and character of the problems faced by the interns:

"My team leader told me to create an Intranet page on a special topic. For the content, I needed to contact the member of another department. When I approached him, he insulted me for no apparent reason and made it impossible to work with him. Afterwards, I talked to one of my team mates, who told me that this guy was known for his irrational behavior and his bad social competence. I wish someone had (a) warned and talked openly to me and (b) that I knew how to behave in such a situation."

This is not unlike situations in project management at large, because whoever works in a project team, usually relies on other people's information and collaboration. The issues of open information sharing and conflict resolution are also touched upon by this short example. It is even relevant to the company training situation above, because there are no boilerplate, standard solutions: nobody could tell this person what to do or not to do without closer examination of the people involved and the prevalent local work place culture. At the same time, having a model of process, or even a process plan, to work from, or to work through, will certainly be an advantage.

The various interventions carried out with the course participants were all geared towards helping them manage situations like the one described.

Figure 6 below shows a screenshot from a virtual classroom session where one of these interventions, or tools, was used: role play. The picture shows also a number of other supporting tools which were all brought into play in order to ease immersion ${ }^{1}$ and make the virtual classroom look more like a real classroom.

These tools included: a scheduling board connected to a public Google Calendar, a picture viewer (in the background), or (not visible) a shared media wall - a shared online workspace - where avatars can access any browserbased application, such as Google Docs, Etherpad, Slideshare etc. Using these tools, we effectively transported group work into the virtual space: during class hours, students (or rather, their avatars) would be distributed into group where they worked on texts, discussed, solved small problems and presented them afterward in the large group.

Though the students were initially confused (not having had any previous 3D experience, they needed a learning period of about two weeks), they quickly adapted to using these tool as avatars.

They also realized the importance of having a portfolio of different methods at their hand to manage virtual communication. And they experienced firsthand that more and

\footnotetext{
${ }^{1}$ Immersion is the process of "losing yourself in the environment" so that your experience your avatar (your electronic representative in the virtual world) as an extension of yourself. It is an important difference between work in interactive virtual 3d words and general (2-dimensional) computer-supported work, such as e.g. computer-guided learning programs or distance communication tools like Skype or Adobe Connect (Sweeney and Adams, 2009).
} 


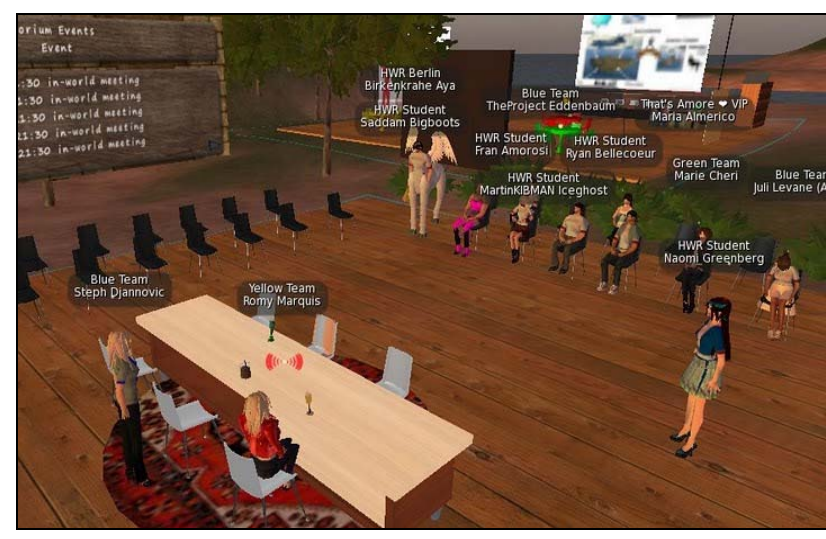

Figure 6. Virtual class meeting

more of work life is carried out, not just supported, by virtual means. One student said:

"I think it can help to improve the communication skills because on the job most meetings will be virtual and it is nice to get an impression how it works and eventually what can go wrong."

The figure also shows a small stage used for a role play (Blatner and Blatner, 1997). We mention the role play here because among the many different training methods that one can use in a real room, role play is beyond doubt one of the most complex involving representatives, improvisational and communication skills. At the same time, when the role play succeeds, it can be a superb intervention and training method.

In the real classroom, role play is often difficult because participants untrained in or unused to self expression, feel embarrassed. Interestingly, in two role play sessions carried out in the virtual world, we found that participants accept the play without difficulty and with great results: the resulting role play situations were lively, the discussion rich, with many more students engaged than in a standard teaching format.

Faced with the need to support participants of an internship supervision course, who were mostly engaged in project work, at a distance, we chose an interactive $3 \mathrm{D}$ virtual world environment to emulate a virtual classroom situation. In order to engage the participants and further their learning experience, the use of mixed media and multiple modes of communication was necessary and was seen as an important by the participants to reach the learning objectives. With regard to more complex group interactions, such as role plays and group work, we found that everything that we'd normally have done in a real classroom, worked in the virtual world as well. Role plays in particular worked better than in the real classroom, judging from the participants' reactions (Gallo, 2010).

Regarding the teacher's side, we found that effective virtual teaching does not require a totally different didactic approach: to engage the students, essentially the same methods can be used that any experienced teacher would use in the real classroom. To establish immersion, however, and to eliminate the frustration that comes from not being able to use, thorough training of the tools and training of the ability to operate the avatar, are absolutely necessary. Once immersion has set in, teacher and student, or team leader and team members, or trainer and trainees, will no longer feel many of the restrictions that they are used to expect from computer-supported training.

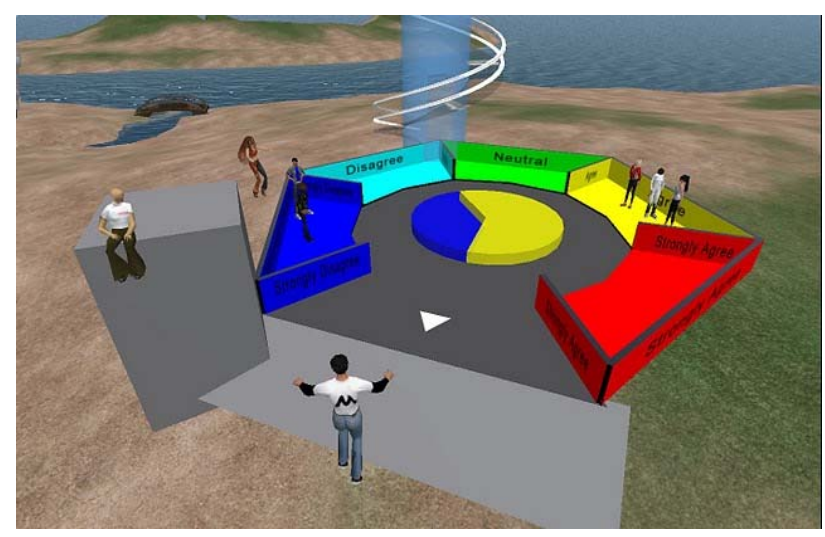

Figure 7. Opinionator - a virtual world object used for instant surveys and feedback

Another tool that we used has no equivalent to a real world tool: the so-called "opinionator" is a structure where avatars can "vote with their feet" by moving into the corner of the object that corresponds to a particular question - the result of he survey is then instantly visually displayed using colors (see Fig. 7). The opinionator was judged by the students as a very attractive means of giving and organizing feedback. It was used to close the sessions in the virtual world with a sample question related to the topic of the session. Often, the students would ask for additional questions to be able to "play" longer with the opinionator.

\section{DISCUSSION}

The results from the participant observation and the narrative interview during the company training show that the consultants are very familiar with the internal processes of the publishing house they train and are well prepared to show the user the examples in the test system. The preparation of the training settings is very individual, the standard training material is rarely used.

We focus in this paper on the key issues of the face-toface training: project management is executed by consultants who are not professional trainers - according to our data, they suffer from a lack of didactic training themselves. They feel that they're less effective when the students experience confusion or conflict.

Another important finding is that the quality of the training depends a lot more on the character and culture of the target group than the initial brief suggests: e.g. in the CR\&R system, someone who closes contracts and someone who deals with accounting requires such different things from the system that it is not advised/practical to train these groups together: it follows that it may be necessary to also take these cultural differences and expectations into account when (a) creating course materials and (b) delivering. Our preliminary results suggest that a systematic approach to these issues could significantly enhance the value of the training.

Our second part of our findings during the practice supervision was meant to test our assumption that most of the group processes used in a systematic way during real classroom sessions (such as group work, role play, discussion etc.) could be transferred to an interactive 3D virtual world. We found this assumption to be true under certain conditions: immersion and interactivity. This is in line with observations made by others (Love et al, 2009; 


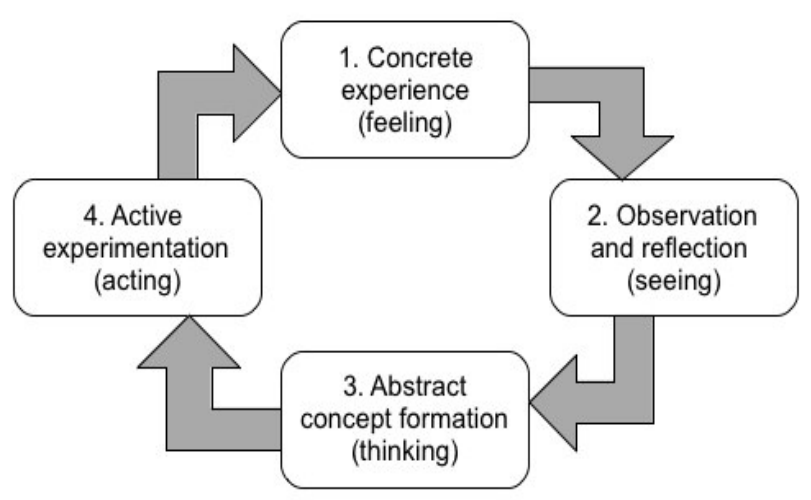

Figure 8. Experiential Learning Cycle (Kolb, Boyatzis, Mainemelis, 1999)

Richardson et al, 2010). To achieve immersion, students need to be trained properly in the new virtual environment. Immersion is both cause and effect: by learning to use their avatar as an extension of themselves, they are further immersed, and by being more immersed, they can make better use of the virtual environment for learning. We've found that it is beneficial to offer the students a number of different modes of learning and group communication. In connection with the company training, where building an atmosphere throughout the training seems to be an important part of the training success, we note that it is easier to build such an atmosphere from scratch, and to control it, in a virtual world (Bartle, 2003).

Overall, we confirm that good learning follows a learning cycle - one prominent example of such a cycle, the "Experiential Learning Cycle", has been propose long ago by Kolb (Kolb, 1984; Kolb et al, 1999, see Fig. 8). It bears similarities to the training lifecycle but is more general and focused on the individual or the group, not on a particular product or process.

Interestingly, this cycle can also form the basis for an explanation of what we observed in the Practice Supervision situation around the onset of participant immersion: the creation of the avatar and its first steps include the "feeling" phase. Virtual classroom activities allow "seeing" and "thinking" even in a group. Finally, a multitude of e-learning tool, accesible to the avatars inside the virtual world allow to create an interactive environment for the students, which is considered one of the key issues for online and especially 3D learning (Kapp and O’Driscoll, 2010).

\section{CONCLUSIONS}

We have identified the key challenges of face-to-face training as part of a multi-national software implementation process: the training process, beginning from the preparation over the training itself until the rework is influenced by various factors. The personality of the trainer, the individuality of each target group of the training has to be taken into account. Different cultures need a consideration on intercultural aspects while preparing each training. The software is implemented in different countries and the user group of each country has it's own specification. Another part of our research project focuses specifically on how to overcome the intercultural aspects. The training process model will be worked out more in detail to get an overview of the training workflow. A meta-model will ensure the transferability to other SMEs. The different technical systems in the training lifecycle (Content Management System, Software Test System, Software Programs like Powerpoint, Word, etc.) which are used by the consultants in each section of the training lifecycle will be reviewed to find out how they use it and which improvements are possible. Our experiences with interactive teaching in virtual 3D environments suggest that a transfer of the techniques developed by us could enrich the training situation especially when immersion is required or when the participants are not able to meet personally. In our future research, we will move from analysis into the creation of process models and into experimenting with $3 \mathrm{D}$ virtual world training settings.

\section{REFERENCES}

[1] Bartle, R. A. (2003), Designing Virtual Worlds, Indianapolis, Indiana

[2] Blatner, A. and Blatner, Allee. (1997), Applications in education, In The art of play: Helping adults reclaim imagination and spontaneity, Philadelphia: Brunner/Mazel-Taylor \& Francis

[3] Birkenkrahe, M., and Scholl, M. (2009), Konzipierung von modularen Weiterbildungsangeboten für KMU an der Schnittstelle von Technik und Kultur zum Thema "Internationales ITgestütztes Projekt- und Wissensmanagement im multikulturellen Umfeld", Berlin School of Economics and Law, Technical University of Applied Science Wildau

[4] Birkenkrahe, M. (2010). Interaktive Lehre im Virtuellen Raum - Ein Beitrag zur Hochschuldidaktik. In: Meyer, S., Pfeiffer, B., (Editor): Die Gute Hochschule - Ideen, Konzepte, Perspektiven, Festschrift für F.H. Rieger. Hochschule für Wirtschaft und Recht Berlin

[5] Birkenkrahe, M. and Gallo, A. (2011) Transfer of Physical Classroom Techniques to the Virtual Classroom During A Practice Supervision Course. To be published in: Journal of Virtual Studies, summer 2011.

[6] Breitner, M. (Ed.) 2010, E-Learning 2010, Physica Verlag HD, retrieved December 12, 2010 from: http://www.springerlink. com/index/10.1007/978-3-7908-2355-4, p.V-VI

[7] Brydon-Miller M., and Greenwood, M. (2003) Why Action Research? http://arj.sagepub.com/content/1/1/9.short

[8] Cavana, R., Delahaya, B., and Sekaran, U. (2001), Applied Business Research: Qualitative and Quantitative Methods, Milton, John Wiley \& Sons Australia Ltd., p. 148-153

[9] Franceschi, K. G., Lee, R. M., and Hinds, D. (2008). Engaging E-Learning in Virtual Worlds: Supporting Group Collaboration. In: Journal of Management Information Systems. vol. 26, ed. 1, Sommer 2009, p. 73 - 100

[10] Gallo A (2010) Die Virtuelle Hochschule (engl. The Virtual University), diploma thesis, Berlin School of Economics and Law

[11] Habermann, F., Schmidt, and K., Kuecher, T. (2005), Knowledge and Learning Tools for Managers: An Empirical Study, retrieved December 12, 2010 from: http://www.wseas.us/elibrary/conferences/crete2004/papers/476-268.pdf

[12] Kapp K M and O’Driscoll T (2010) Learning in 3D - Adding a New Dimension to Enterprise Learning and Collaboration, San Francisco: Pfeiffer/Wiley.

[13] Kolb, D. A., (1984). Experiential learning: Experience as the source of learning and development. New Jersey: Prentice-Hall.

[14] Kolb, D. A., Boyatzis, R. E., and Mainemelis, C. (1999) Experiential Learning Theory: Previous Research and New Directions; in: R. J. Sternberg and L. F. Zhang (Eds.), Perspectives on cognitive, learning, and thinking styles. NJ: Lawrence Erlbaum, 2000; pp.

[15] Love, E., Ross, S. C., and Wilhelm, W. (2009). Opportunities and Challenges for Business Education in Second Life. In: Wankel, C./Kingsley, J. (2009). Higher Education in Virtual Worlds - Teaching and Learning in Second Life, Bingley 
[16] Mayring, P. (2002), Einführung in die Qualitative Sozialforschung, S. 80-85, Beltz Verlag

[17] Plagemann, J. (2010). Hochschulmarketing - Empfehlungen von Marketingmaßnahmen zur Unterstützung des Aufbaus einer virtuellen Präsenz in Second Life für die HWR Berlin. Diplomarbeit. Hochschule für Wirtschaft und Recht Berlin

[18] Richardson, D. and Molka-Danielsen, J. (2010). Assessing Student Performance. In: Deutschmann, M./Molka-Danielsen, J. (2010). Learning and Teaching in the Virtual World of Second Life, Trondheim

[19] Schloesser, M. (2010), Besser Lernen im Web 2.0, Handelsblatt, retrieved December 12, 2010, from: http://www.handelsblatt.com/internet-besser-lernen-im-web-20;2637625

[20] Sweeney, B. and Adams, A. (2009) Virtual world users evaluated according to environment design, task based and affective attention measures. In: Proceedings of the 23rd British HCI Group Annual Conference on People and Computers

\section{AUTHORS}

Marcus Birkenkrahe is with the Department of Economics, Berlin School of Economics and Law, Badensche Str. 52, 10825 Berlin, Germany (msb@hwr-berlin.de).

Stefanie Quade is with the Department of Economics, Berlin School of Economics and Law, Badensche Str 52, 10825 Berlin, Germany (stefanie.quade@hwr-berlin.de).

Frank Habermann is with the Department of Economics, Berlin School of Economics and Law, Badensche Str 52, 10825 Berlin, Germany (frank.habermann@hwrberlin.de).

This work was supported in part by the BMBF/FHProfUnt research programme InterComp SME 2.0 and by the European Social Fund.

This article is an extended version from a paper presented at the International Conference ICELW2011, held June 8th-10th, in New York, NY, USA. Received 27 june 2011. Published as resubmitted by the authors 15 October 2011. 